\title{
Long-term proton pump inhibitor usage and the association with pancreatic cancer in Sweden
}

\author{
Nele Brusselaers ${ }^{1,2,3}(1) \cdot$ Omid Sadr-Azodi $^{4,5} \cdot$ Lars Engstrand $^{1,2}$
}

Received: 12 September 2019/Accepted: 26 November 2019/Published online: 6 December 2019

(C) The Author(s) 2019

\begin{abstract}
Background The long-term safety of proton pump inhibitors (PPIs) is increasingly questioned. The aim of our study was to assess the risk of pancreatic cancer among longterm PPI users in Sweden.

Methods This population-based nationwide Swedish cohort study including 796,492 adult long-term PPI users has been used to calculate the standardized incidence rate ratios (SIRs) and 95\% confidence intervals (CI) for pancreatic cancer, stratifying by indications of use, age, sex, and duration of use. The risk among all 20,210 long-term H2-receptor antagonist users was assessed as comparison. Results Pancreatic cancer was found in 1733 long-term PPI users, and 25 H2-receptor antagonist users. For PPI users, the risk of pancreatic cancer was increased overall (SIRs $=2.22 ; 95 \%$ CI 2.12-2.32) and in all subgroup analyses, with the highest risk among PPI-users younger than 40 years $(\mathrm{SIR}=8.90,95 \%$ CI $4.26-16.37)$, and among individuals with a history of Helicobacter pylori
\end{abstract}

Nele Brusselaers

Nele.Brusselaers@ki.se

1 Department of Microbiology, Tumor and Cell Biology, Centre for Translational Microbiome Research, Karolinska Institutet, Karolinska Hospital, Visionsgatan 4, 17164 Stockholm, Sweden

2 Science for Life Laboratory (SciLifeLab), Stockholm, Sweden

3 Department of Head and Skin, Faculty of Medicine, Ghent University, Ghent, Belgium

4 Clinical Epidemiology Division, Department of Medicine Solna, Karolinska Institutet, Stockholm, Sweden

5 Department of Surgery, St Göran Hospital, Stockholm, Sweden
$(\mathrm{SIR}=2.99,95 \%$ CI 2.54-3.49). After the first year after enrolment (during which PPI use may be because of early symptoms of pancreatic cancer), the risk remained increased over time, with SIR $=1.57$ (95\% CI 1.38-1.76) after 5 years. No associations were found for H2-receptor antagonists ( $\mathrm{SIR}=1.02,95 \%$ CI $0.66-1.51$ ).

Conclusions This large study showed an increased risk of pancreatic cancer in long-term users of PPIs in Sweden, in particular among the youngest users.

Keywords Pancreatic neoplasms - Pancreas · 2Pyridinylmethylsulfinylbenzimidazoles · Gastric acid · PPIs
Abbreviations
CI Confidence interval
H2RA Histamine-2 receptor antagonist
PPI Proton pump inhibitor
SIR Standardized incidence ratio

\section{Introduction}

One of the frequently debated questions in gastro-enterology is if the long-term use of proton pump inhibitors (PPI) is carcinogenic, and if benefits outweigh the risks for all individuals. Proton pump inhibitors are by far the most commonly prescribed medications for almost every problem or discomfort of the upper-gastrointestinal tract, including gastro-esophageal reflux, (prevention of) peptic ulcers, gastroduodenitis, dyspepsia or eradication of Helicobacter pylori $[1,2]$. PPIs are commercialized in the 
1980s, and since they are extremely potent in suppressing gastric acid production, close monitoring was initially required with endoscopies and regular follow-up. Nowadays, PPIs are available over-the-counter in many countries, and easily prescribed yet not easily discontinued, leading to a steadily increasing amount of long-term users [1, 3-6]. Noteworthy is that previous studies reported $25-70 \%$ of inappropriate use of prescribed PPIs, contributing to polypharmacy and potential drug-drug interactions [1, 7].

Nevertheless, the list of potential side-effects related to long-term PPI use is increasing, including among others, chronic kidney disease, osteoporosis and fractures, Clostridium difficile infections, community acquired pneumonia, cardiac diseases, and even increased mortality [8-19]. An increasing number of studies have also investigated the risk of cancer with most evidence existing for gastric, colorectal and pancreatic cancer. The two metaanalyses on gastric cancer (in total including 8 different studies) concluded that there may be an increased risk in particular when used over longer periods of time [20, 21]. Yet, the two meta-analyses evaluating colorectal cancer (including 5 different studies) did not find strong support for an association [22, 23], although 2 more studies have been published since showing a significantly increased risks $[24,25]$. For pancreatic cancer, the 12th most common cancer type, with only $8 \%$ 5-year survival [26], we have identified 6 case-control studies [27-32] and 1 cohort study [33] of which 3 studies clearly show statistically increased risks (up to 9-times higher than non-users) [27, 29, 30]. Yet, methodological heterogeneity and selection bias may challenge the interpretation of these findings. Therefore, our aim was to assess the risk of pancreatic cancer in our previously used Swedish population-based cohort study [34-36] to compare the risk of pancreatic cancer in including individuals receiving PPI maintenance therapy with the expected risk based on the total Swedish population.

\section{Methods}

This nationwide Swedish population-based cohort study was designed to compare the risk of pancreatic cancer among adults ( $\geq 18$ years) exposed to long-term PPIs compared to the Swedish background population of the same sex, age, and calendar year, following an a-priori established study protocol. The study results are reported according to the STROBE statement (Strengthening the Reporting of Observational Studies in Epidemiology) for cohort studies. This cohort has been described in detail elsewhere [34, 36], and was approved by the Regional Ethical Review Board in Stockholm (2014/1291-31/4).
This study has been performed in accordance with the ethical standards laid down in the 1964 Declaration of Helsinki and later amendments, yet informed consent was not required because of the registry-based nature of the data. All individuals, without a history of cancer, were enrolled between 1st July 2005 (start of the Swedish Prescribed Drug Registry) to 31st December 2012, and followed up until the occurrence of any cancer, death or 31st December 2012 (i.e., end of data collection for Cancer Registry), whichever occurred first.

\section{Exposure}

PPI use was defined by the Anatomic Therapeutic Chemical classification (ATC) system code A02BC, as registered in the Swedish Prescribed Drug Registry. Long-term PPI use was defined as $\geq 180$ days of exposure to PPI during the study period before onset of any cancer, approximating 1 month per year or more if close to the maximum followup of 7.5 years. This total cumulative administered PPI dosage is estimated by adding the defined daily dose per package (DDDp), which takes the potency of the drug into account as well as the prescribed quantity with DDD being the assumed average maintenance dose per day for a drug used for its main indication in adults according to the World Health Organization. For comparison reasons, the risk of pancreatic cancer was also evaluated among all adults who received $\geq 180$ days of exposure to H2-receptor antagonists, a drug class with similar indications (ATC code A02BA). All individuals who received both $\geq 180$ days of PPIs and $\geq 180$ days of H2RA $(N=25,726$ [36] were excluded from all analyses. PPIs are also available over-the-counter in Sweden since 1999 [6], yet only in small packages (so at a higher price per dose [37], so we can assume that long-term users have the large majority of their PPI doses prescribed.

\section{Outcome}

The outcome was cancer of the pancreas, as (compulsory) registered in the nationwide Cancer Register and defined by the $\mathrm{C} 25$ code of the International Classification of Diseases, $10^{\text {th }}$ edition (ICD 10). Pancreatic adenocarcinoma was defined by the histopathological code 096 .

\section{Potential confounders/covariates}

Age was grouped by age of first PPI prescription and categorized as 18-40 years, 40-49 years, 50-59 years, 60-69 years, and $\geq 70$ years. Sex was grouped as male or female, and calendar period, as 2005-2006, 2007-2009 and 2010-2012. There was no missing information on these 3 variables. 
Potential confounding by indication was evaluated by subgroup analyses by indications for gastric acid suppressive therapy. Although these indications are not known as strong risk factors for pancreatic cancer, a potential protective effect has been described for long-term aspirin or other non-steroidal anti-inflammatory drugs (NSAIDs) [38]. The following 6 subgroups were assessed, as defined earlier based on the Patient Registry and/or Prescribed Drug Registry: [29, 30] (1) gastro-esophageal reflux disease; (2) peptic ulcers; (3) gastroduodenitis; (4) Helicobacter pylori eradication/infection, long-term ( $\geq 180$ days during study period) users of (5) aspirin (ATC codes B01AC06, N02BA) or (6) other NSAIDs (ATC code M01A) without any of the selected gastrointestinal indications (including the less prevalent indications dyspepsia, Barrett esophagus and Zollinger-Ellison syndrome, which were recorded in $\leq 5 \%$ of the present cohort and therefore not assessed separately). No indication of therapy was registered for approximately $22 \%$ of the cohort $[34,36]$.

An additional subgroup analyses was conducted for individuals with diabetes mellitus, a known risk factor for pancreatic cancer, as defined by the use of any "drugs used in diabetes" (ATC code $\underline{\mathrm{A} 10}$ ) before the diagnosis of any cancer.

\section{Statistical analyses}

The risk of developing pancreatic cancer was assessed by comparing the observed risk among long-term users of PPIs and the expected risk according to the Swedish background population of the same age, sex and calendar period, by means of standardized incidence rate ratios (SIRs) and 95\% confidence intervals (CI) [39]. Expected incidence rates were calculated based on the Swedish Cancer Registry and Total Population Registry [40]. Time of follow-up was calculated from the dispense date of the first prescription of PPI within the study period, until death, cancer or end of study period (December 2012), whichever occurred first. The analyses were stratified by sex, age, indication, and diabetes mellitus as described above, and subgroup analyses were conducted for adenocarcinoma only.

The effect of duration of treatment was assessed by looking at the risk in relation to the time since the first PPI prescription, categorized as $<1.0$ year, 1.0-2.9 years, 3.0-4.9 years and more than 5.0 years, as described earlier [35]. These groups are not mutually exclusive (with one individual potential contributing person-time to different groups) as would be the case when using the total estimated accumulated dosage based on the DDD, with the associated risk of immortal time-bias in the groups with higher dosages.

\section{Results}

The characteristics of all 796,492 long-term PPI users are described in Table 1. Approximately $59 \%$ of the cohort was female, and $34 \%$ was 70 years or older. Long-term aspirin and other NSAIDs use were the most common indications, respectively, in $35 \%$ and $30 \%$ of the cohort; with relatively more male aspirin users, and more female NSAIDs users. Gastro-esophageal reflux, gastroduodenitis, peptic ulcers, and Helicobacter pylori eradication/infection were recorded for, respectively, $25 \%, 13 \%, 10 \%$, and $7 \%$ of the cohort. Diabetes drugs were used prior cancer diagnosis by $3.5 \%$ of women and $5.0 \%$ of men.

\section{Risk of pancreatic cancer by age and sex}

In total, 1733 individuals developed pancreatic cancer, of which $80.4 \%$ were adenocarcinomas. The overall SIR of pancreatic cancer among long-term PPI users compared to the Swedish background population, was 2.22 (95\% CI 2.12-2.32). The risk estimates were slightly higher for men $(\mathrm{SIR}=2.46,95 \%$ CI 2.30-2.64) than women $(\mathrm{SIR}=2.04$, 95\% CI 2.30-2.64) (Table 2). The highest risk estimate was found for the youngest age group ( $\mathrm{SIR}=8.90,95 \% \mathrm{CI}$ 4.26-16.37), with the risk estimates decreasing by age (SIR $=1.81,95 \%$ CI $1.69-1.94$ for those $\geq 70$ years). The $95 \% \mathrm{CI}$ of the 4 oldest age-groups did not overlap indicating a statistically significant decrease in risk with increasing age. Similar results were found when restricting to adenocarcinomas.

\section{Indications of use}

Compared to the Swedish background population, the risk of pancreatic cancer was higher among PPI long-term users for all indication groups, with the highest SIRs for those with a history of Helicobacter pylori infection/eradication (SIR $=2.99,95 \% 2.54-3.49)$, and the lowest risk for longterm aspirin users ( $\mathrm{SIR}=1.55,95 \%$ 1.36-1.77), again with similar findings for adenocarcinoma only (Table 2). Figure 1 shows the SIRs for each indication per age group, with the youngest 3 age-groups merged to obtain sufficient power. The SIRs were 5-6 times higher for those younger than 60 with peptic ulcers or gastroduodenitis, and the lowest SIR (1.40, 95\% 1.19-1.64) was found for long-term aspirin users of 70 years or older.

\section{Risk among individuals with diabetes mellitus}

The SIRs for pancreatic cancer in this group was 3.76 (95\% CI 3.19-4.41) and 3.68 (95\% CI 3.05-4.41) for pancreatic adenocarcinoma (Table 2). 
Table 1 Description of the all long-term users of proton pump inhibitors (defined as $\geq 180$ days accumulated use) in Sweden during 2005-2012

\begin{tabular}{|c|c|c|c|}
\hline & $\begin{array}{l}\text { Total } \\
\text { Number }(\%)\end{array}$ & $\begin{array}{l}\text { Women } \\
\text { Number (\%) }\end{array}$ & $\begin{array}{l}\text { Men } \\
\text { Number (\%) }\end{array}$ \\
\hline Total & $796,492(100)$ & $465,840(58.5)$ & $330,652(41.5)$ \\
\hline \multicolumn{4}{|l|}{ Age } \\
\hline$<40$ years & $88,775(11.2)$ & $52,780(11.3)$ & 35,995 (10.9) \\
\hline $40-49$ years & $103,784(13.0)$ & $59,440(12.8)$ & $44,344(13.4)$ \\
\hline $50-59$ years & $155,625(19.5)$ & $86,756(18.6)$ & $68,869(20.8)$ \\
\hline $60-69$ years & $177,610(22.3)$ & $98,012(21.0)$ & $79,598(24.1)$ \\
\hline$\geq 70$ years & $270,698(34.0)$ & $168,852(36.3)$ & $101,846(30.8)$ \\
\hline \multicolumn{4}{|l|}{ Calendar period } \\
\hline 2005-2006 & $437,229(54.9)$ & $258,700(55.5)$ & $178,529(54.0)$ \\
\hline $2007-2009$ & $227,142(28.5)$ & $132,730(28.5)$ & $94,412(28.6)$ \\
\hline 2010-2012 & $132,121(16.6)$ & $74,410(16.0)$ & $57,711(17.5)$ \\
\hline \multicolumn{4}{|l|}{ Indications of use } \\
\hline Gastro-esophageal reflux & $201,744(25.3)$ & $109,675(23.5)$ & $92,069(27.8)$ \\
\hline Peptic ulcers & $79,546(10.0)$ & $40,255(8.6)$ & 39,291 (11.9) \\
\hline Gastroduodenitis & $104,903(13.2)$ & $59,654(12.8)$ & $45,249(13.7)$ \\
\hline Helicobacter pylori infection/eradication & $58,340(7.3)$ & $32,082(6.9)$ & $26,258(7.9)$ \\
\hline Aspirin maintenance therapy & $276,941(34.8)$ & $147,180(31.6)$ & $129,761(39.2)$ \\
\hline NSAIDs maintenance therapy & $241,777(30.3)$ & $160,632(34.5)$ & $81,145(24.5)$ \\
\hline Diabetes drugs before cancer diagnosis & $33,384(4.2)$ & $16,531(3.5)$ & $16,853(5.0)$ \\
\hline Pancreatic cancer & $1,733(0.21)$ & $917(0.20)$ & $816(0.25)$ \\
\hline Pancreatic adenocarcinoma & $1394(0.18)$ & $742(0.16)$ & $652(0.20)$ \\
\hline
\end{tabular}

NSAIDs non-steroidal anti-inflammatory drugs

\section{Duration of treatment}

During the first year of treatment, the SIRs was 4.35 (95\% CI 4.03-4.68), and even 9.82 (95\% CI 8.39-11.42) among those younger than 60 years (Fig. 2). After this first year, the risk was still increased, and seemed to increase over time, from SIR $=1.28$ (95\% CI 1.16-1.40) between 1 and 3 years after treatment initiation to $1.57 \quad(95 \%$ CI 1.38-1.76) after 5 years, with again similar findings when restricting to adenocarcinomas. Figure 2 shows the results stratified by age, and this apparent increase over time after the first year was most consistent among those younger than 60 years (from SIR $=1.46,95 \%$ CI $1.12-1.88$ to $\mathrm{SIR}=2.16,95 \%$ CI 1.64-2.78).

\section{H2-receptor antagonists}

Among the 20,210 long-term users of H2-receptor antagonists, 25 cases of pancreatic cancer occurred for 113,961 person years of follow-up. The analyses did not find evidence for an association, with $\mathrm{SIR}=1.02(95 \%$ CI 0.66-1.51) overall, and SIR $=0.92(0.49-1.57)$ among women and SIR $=1.17(0.60-2.04)$.

\section{Discussion}

This large population-based study assessing long-term use of PPIs showed an overall doubled risk of pancreatic cancer among long-term PPI users compared to Swedish background population, in particular among the younger age-groups. Disregarding the first year of use (which may reflect PPI use because of early symptoms, reverse causality), the risk increased over time since initiating treatment in particular among the youngest age-groups, and the risk increase was shown for all investigated indications of use. There was no association between the H2-receptor antagonist use and pancreatic cancer.

The strengths of this study are the population-based design, the study size with almost 800,000 long-term PPI users with 4 million years of follow-up; and over 20,000 H2-receptor users as comparison group. The, to our knowledge, largest studies previously published describing this association with pancreatic cancer, only included almost 50,000 PPI users from Korea [33]; and 10,500 H2receptor antagonist users in Australia, Canada and the United States [32]. The maximal duration of follow-up in the previously published cohort study was 12 years, compared to the 7.5 years in the present study. All PPI use in the present study is based on prescriptions, eliminating the 
Table 2 The risk of pancreatic cancer and pancreatic adenocarcinoma for all long-term proton pump inhibitor users in Sweden (defined as $\geq 180$ days accumulated use), presented as standardized incidence rate ratios (SIRs) and $95 \%$ confidence intervals (CI)

\begin{tabular}{|c|c|c|c|c|c|}
\hline & \multirow[t]{2}{*}{ Person years } & \multicolumn{2}{|l|}{ Total } & \multicolumn{2}{|c|}{ Adenocarcinoma } \\
\hline & & $N(\%)$ & SIRs $(95 \%$ CI $)$ & $N(\%)$ & SIRs $(95 \%$ CI $)$ \\
\hline Total & $3,828,553$ & 1733 & $2.22(2.12-2.32)$ & 1394 & $2.26(2.14-2.38)$ \\
\hline \multicolumn{6}{|l|}{ Sex } \\
\hline Women & $2,275,213$ & 917 & $2.04(1.91-2.17)$ & 742 & $2.10(1.95-2.26)$ \\
\hline Men & $1,553,340$ & 816 & $2.46(2.30-2.64)$ & 652 & $2.46(2.28-2.66)$ \\
\hline \multicolumn{6}{|l|}{ Age } \\
\hline$<40$ years & 333,857 & 10 & $8.90(4.26-16.37)$ & 7 & $12.30(4.93-25.34)$ \\
\hline $40-49$ years & 475,113 & 65 & $5.93(4.58-7.56)$ & 54 & $6.62(4.97-8.63)$ \\
\hline $50-59$ years & 729,786 & 230 & $3.36(2.94-3.82)$ & 187 & $3.29(2.84-3.80)$ \\
\hline $60-69$ years & 954,060 & 602 & $2.46(2.26-2.66)$ & 520 & $2.47(2.27-2.70)$ \\
\hline$\geq 70$ years & $1,335,737$ & 826 & $1.81(1.69-1.94)$ & 626 & $1.83(1.69-1.98)$ \\
\hline \multicolumn{6}{|l|}{ Indications of use } \\
\hline Gastro-esophageal reflux & 979,793 & 409 & $2.06(1.86-2.27)$ & 331 & $2.01(1.87-2.33)$ \\
\hline Peptic ulcers & 359,158 & 234 & $2.59(2.27-2.94)$ & 182 & $2.56(2.20-2.96)$ \\
\hline Gastroduodenitis & 526,036 & 307 & $2.75(2.45-3.08)$ & 245 & $2.78(2.44-3.15)$ \\
\hline Helicobacter pylori infection/eradication & 288,390 & 160 & $2.99(2.54-3.49)$ & 121 & $2.85(2.37-3.41)$ \\
\hline Long-term aspirin use $\mathrm{u}^{\mathrm{a}}$ & 497,202 & 222 & $1.55(1.36-1.77)$ & 173 & $1.56(1.33-1.81)$ \\
\hline Long-term NSAIDs use ${ }^{\mathrm{a}}$ & 571,664 & 210 & $2.33(2.03-2.67)$ & 174 & $2.40(2.06-2.79)$ \\
\hline Diabetes mellitus drugs & 164,936 & 152 & $3.76(3.19-4.41)$ & 118 & $3.68(3.05-4.41)$ \\
\hline \multicolumn{6}{|l|}{ Time since start PPIs } \\
\hline First year & 979,007 & 689 & $4.35(4.03-4.68)$ & 589 & $4.62(4.25-5.01)$ \\
\hline $1-3$ years & $2,340,030$ & 414 & $1.28(1.16-1.40)$ & 331 & $1.25(1.12-1.39)$ \\
\hline $3-5$ years & $1,159,914$ & 362 & $1.40(1.26-1.55)$ & 286 & $1.40(1.25-1.58)$ \\
\hline$>5$ years & 747,495 & 268 & $1.57(1.38-1.76)$ & 188 & $1.45(1.25-1.67)$ \\
\hline
\end{tabular}

NSAIDs non-steroidal anti-inflammatory drugs

${ }^{a}$ No other gastrointestinal indications recorded

risk of misclassification because of recall-bias, in particular because the Swedish Prescribed Drug registry is virtually complete, although no data are available on in-hospital use [41]. Yet, some long-term users may not have been identified if (part of) their PPI use was obtained over-thecounter instead of by prescription [6]. We also lack information on PPI use before July 2005, but previous studies have shown that PPI use overall, and long-term PPI use are increasing over time, and that discontinuation of treatment is often over-looked by physicians [1-5]. Therefore, it is difficult to distinguish between prevalent and incident PPI users, although we assume that many of those exposed in 2005 were already users prior to enrolment in the present study.

We defined long-term use as an accumulated use of 6 months of more, which was considerably stricter than other studies looking at PPI use and the risk of gastric cancer (defined as current use, or minimally 1-2 prescriptions) [20], and pancreatic cancer, all defining PPI use as $\geq 1$ prescription [27-33]. Long-term use ( $>6$ months has only been approved by the Food and Drug Administration for pathological hypersecretory conditions such as the Zollinger-Ellison syndrome; and erosive esophagitis (based on study data $<12$ months) [42].

Since long-term PPI use is nevertheless common (approximately $11 \%$ of all Swedish adults), using the total Swedish background population to calculate expected risks, may have diluted the overall effect $[34,36,43]$. The total accumulated dosage of PPIs may correlate with an increasing risk of pancreatic cancer. Yet, as described earlier, immortal time-bias is a concern [35], and therefore only data based on time since start of PPI treatment are calculated and presented. The popularity of PPI use also makes it unfeasible to find a comparison group with the same (severity of) symptoms and indications for treatment not receiving treatment with PPIs or H2-receptor antagonists, the most popular yet clearly less common alternative. Although all results are standardized for age, sex and 
Fig. 1 The risk of pancreatic cancer among long-term users of proton pump inhibitors (PPIs) (defined as $\geq 180$ days accumulated use) compared to the Swedish background common indications of use, stratified per age-group population, for the most

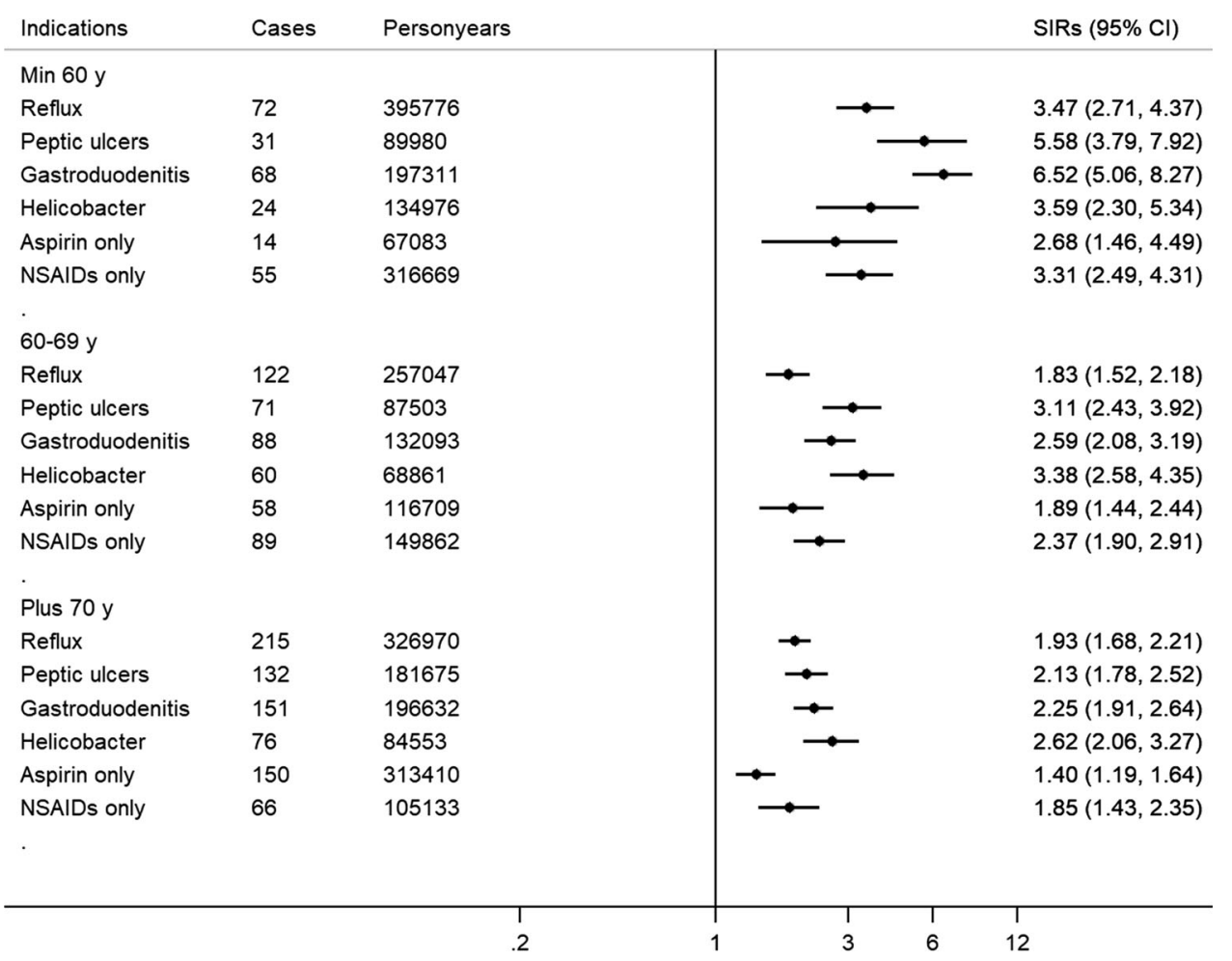

calendar period, residual confounding may remain. Smoking, obesity and diabetes, known risk factors for pancreatic cancer which may also be related to PPI intake, are unfortunately not collected nationwide for calculations of SIRs. According to the Public Health Agency of Sweden, approximately $50 \%$ of the Swedish adults is overweight or obese, and 8-11\% smoked daily in 2016 [44]. The subgroup analyses on individuals using diabetes medication also showed increased risks of pancreatic cancer, but because of the low proportion of PPI users $(4.2 \%)$ diabetes cannot explain the increased overall risk. However, it is unlikely that residual confounding would fully explain the increasing risk of pancreatic cancer over time. Furthermore, the lack of association between H2-antagonists and pancreatic cancer diminish the possibility of indication bias as an explanation for our findings.

Drawing causal relationships in the PPI versus cancer story is challenging [43], in particular because PPIs are by far the most commonly prescribed drug for most of its' indications. In Sweden, long-term use of PPIs is almost 30 times more common than H2-receptor antagonists use when disregarding those using both drug classes during the study period [43]. Some of the indications may be unrecognized risk factors for pancreatic cancer, or actually be early symptoms of pancreatic cancer. This may explain the very high SIRs during the first year of follow-up, indicating reverse causality or protopathic bias, in particular among the youngest age group who may seem unlikely to be at risk for pancreatic cancer (potentially delaying diagnosis).
Yet, all individuals required an estimated accumulated duration of exposure of at least 6 months. This should have eliminated those diagnosed shortly after initiating PPI treatment, yet an increased risk during that first year was not unlikely as also seen in our previous papers on gastric and esophageal cancer (with 7-9 times increased SIRs compared to the background population) [35]. Since pancreatic cancer is a relatively aggressive cancer (with 80-85\% presenting with locally advanced or distant metastatic disease at time of diagnosis [45], it is however unlikely that early symptoms have been unrecognized longer than 1 year. In the early stage, most patients are asymptomatic [46]. Previous studies described abdominal pain in $25 \%$ of individuals up to 6 months prior to diagnosis [47], and only few symptoms occurring more than 6 months before diagnosis: back pain, shoulder pain, dysphagia, changes in bowel habits, and lethargy [46, 48].

This strongly reduces the risk of reverse causality in those analyses for the time periods after the first year. Importantly, the lack of association between H2-antagonists (with similar indications as PPI) and pancreatic cancer further strengthen the hypothesis that long-term PPI use may be carcinogenic. Finally, the increase in risk over time after this first year, both overall and for adenocarcinoma only, also supports our hypothesis that PPI may be an independent risk factor for pancreatic cancer.

As mentioned above, some epidemiological studies have been conducted to investigate the association between PPI use and pancreatic cancer, with 3 out of 7 studies showing 


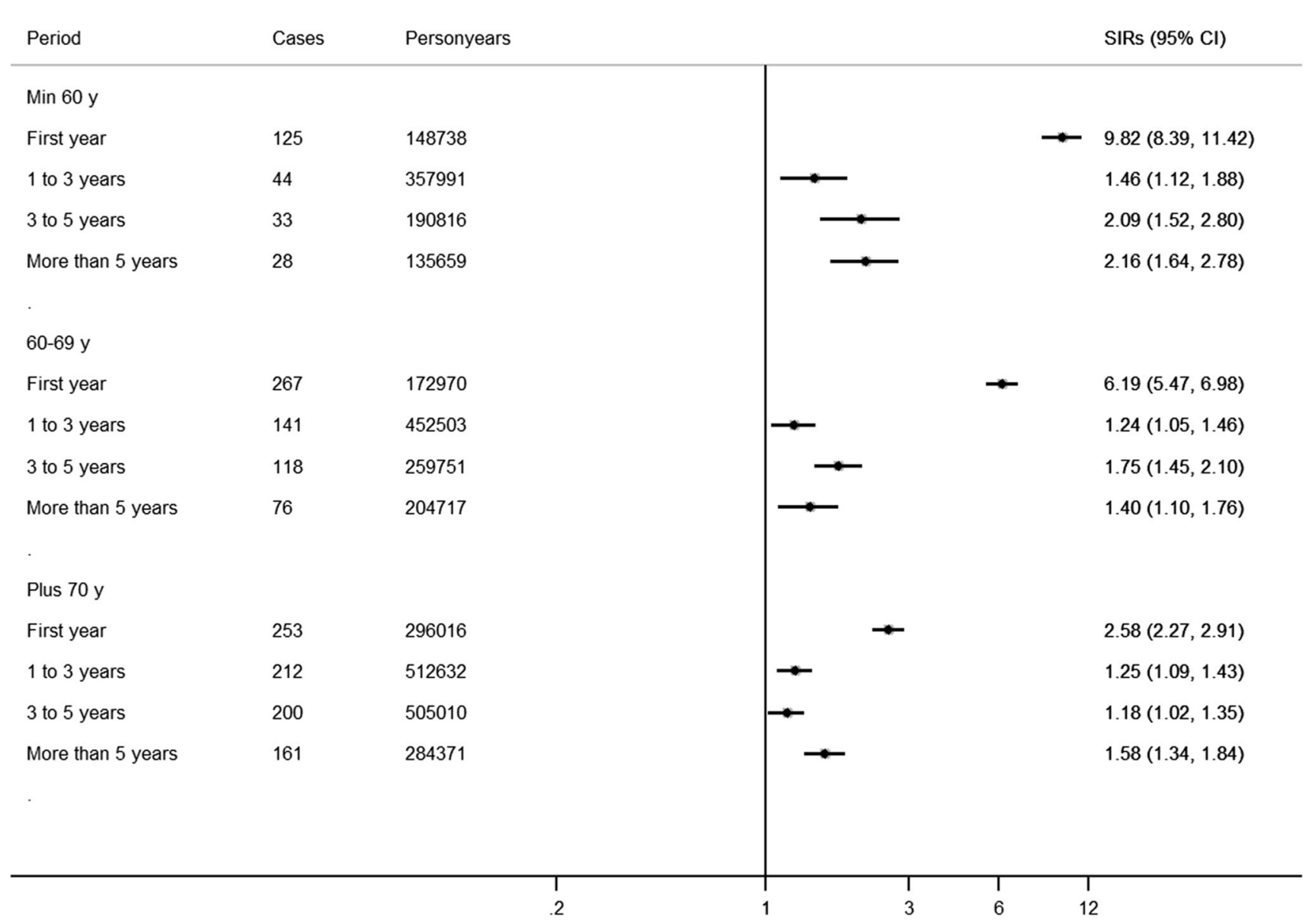

Fig. 2 The risk of pancreatic cancer among long-term users of proton pump inhibitors (PPIs) (defined as $\geq 180$ days accumulated use) compared to the Swedish background population, stratified per age-group and time since initiation of treatment

strongly increased risks [27, 29, 30], and 4 without any statistical significant difference [28, 31-33]. Previous epidemiological studies also described increased risks of periampullary cancer, cholangitis and cholecystitis [49-51]. Pre-clinical studies have shown that PPIs can create hypoacidity and consequently hypergastrinemia which may result in an overgrowth of pancreatic cells [33, 52]. PPIs have also been described as the drug-group with the largest effect on the lower gut microbiome based on populationbased studies [53-56]. Yet, by reducing gastric acidity in the stomach, the bactericidal effect will also be reduced, leading to changes in the microbiome of the upper-gastrointestinal tract or bacterial overgrowth of potential harmful bacteria [56]. Regarding the results of the present study, and our previous studies on gastric and esophageal cancer showing similar age-dependent effects, a more thorough investigation of the effect of PPIs on the microbiome for different age-groups seems warranted. The clinical implications of this apparent increased relative risk of pancreatic cancer may be limited since the absolute, lifetime risk of pancreatic cancer is low (approximately 1.5\% [57]. Yet, since pancreatic cancer is usually diagnosed late, usually in individuals between 60-80 years [46], it may be important to be aware of this risk in particular in young long-term PPI users, because the symptoms are vague, and may suggest a gastro-esophageal origin. Unfortunately, the available data did not allow a more in depth analysis of duration/cumulative dosage among the youngest age-group because of the low absolute risk.

To conclude, this paper provides evidence for an independent association between long-term PPI use and the risk of pancreatic cancer, based on a large, population-based nationwide cohort study. Especially the strong increase among the youngest age-groups warrant attention, since this may indicate a stronger risk among young individuals and a higher risk of delayed diagnosis if PPIs are initiated and continued for early symptoms without more thorough examination.

Acknowledgements Open access funding provided by Karolinska Institute.

Author contributions All authors (NB, OSA, and LE) were involved in the concept and design of the study; NB collected the data and conducted the analyses, the results were interpreted by all authors 
(NB, OSA, LE), NB drafted the manuscript which was critically revised and approved by OSA and LE. NB obtained the funding for the project and is the guarantor.

Funding This work was supported by Svenska Lakaresallskapet (2018, SLS-788751), Bengt Ihres foundation (2018, SLS-788731), Gastrologisk forskningsfond (2018, SLS-783091). These were not involved in the study design, collecting or interpreting the data or drafting the manuscript.

\section{Compliance with ethical standards}

Conflicts of interest None declared (financial and personal).

Open Access This article is licensed under a Creative Commons Attribution 4.0 International License, which permits use, sharing, adaptation, distribution and reproduction in any medium or format, as long as you give appropriate credit to the original author(s) and the source, provide a link to the Creative Commons licence, and indicate if changes were made. The images or other third party material in this article are included in the article's Creative Commons licence, unless indicated otherwise in a credit line to the material. If material is not included in the article's Creative Commons licence and your intended use is not permitted by statutory regulation or exceeds the permitted use, you will need to obtain permission directly from the copyright holder. To view a copy of this licence, visit http://creativecommons. org/licenses/by/4.0/.

\section{References}

1. Boghossian TA, Rashid FJ, Thompson W, et al. Deprescribing versus continuation of chronic proton pump inhibitor use in adults. Cochrane Database Syst Rev. 2017;3:CD011969.

2. Farrell B, Pottie K, Thompson W, et al. Deprescribing proton pump inhibitors: evidence-based clinical practice guideline. Can Fam Physician (Medecin de famille canadien). 2017;63:354-64.

3. Halfdanarson OO, Pottegard A, Bjornsson ES, et al. Proton-pump inhibitors among adults: a nationwide drug-utilization study. Ther Adv Gastroenterol. 2018;11:1756284818777943.

4. Pottegard A, Broe A, Hallas J, et al. Use of proton-pump inhibitors among adults: a Danish nationwide drug utilization study. Ther Adv Gastroenterol. 2016;9:671-8.

5. Kim J, Blackett JW, Jodorkovsky D. Strategies for effective discontinuation of proton pump inhibitors. Curr Gastroenterol Rep. 2018;20:27.

6. Cohen J. Switching omeprazole in Sweden and the United States. Am J Ther. 2003;10:370-6.

7. Yucel E, Sancar M, Yucel A, et al. Adverse drug reactions due to drug-drug interactions with proton pump inhibitors: assessment of systematic reviews with AMSTAR method. Expert Opin Drug Saf. 2016;15:223-36.

8. Xie Y, Bowe B, Yan Y, et al. Estimates of all cause mortality and cause specific mortality associated with proton pump inhibitors among US veterans: cohort study. BMJ (Clinical research ed). 2019;365:11580.

9. Xie Y, Bowe B, Li T, et al. Risk of death among users of proton pump inhibitors: a longitudinal observational cohort study of United States veterans. BMJ Open. 2017;7:e015735.

10. Sun J, Sun H, Cui M, et al. The use of anti-ulcer agents and the risk of chronic kidney disease: a meta-analysis. Int Urol Nephrol. 2018;50:1835-43.

11. Qiu T, Zhou J, Zhang C. Acid-suppressive drugs and risk of kidney disease: a systematic review and meta-analysis. J Gastroenterol Hepatol. 2018;33:1566-73.
12. Nochaiwong S, Ruengorn $\mathrm{C}$, Awiphan R, et al. The association between proton pump inhibitor use and the risk of adverse kidney outcomes: a systematic review and meta-analysis. Nephrol Dial Transplant Off Publ Eur Dial Transpl Assoc Eur Ren Assoc. 2018;33:331-42.

13. Poly TN, Islam MM, Yang HC, et al. Proton pump inhibitors and risk of hip fracture: a meta-analysis of observational studies. Osteoporos Int J Establ Result Coop Between Eur Found Osteoporos Natl Osteoporos Found USA. 2019;30:103-14.

14. Islam MM, Poly TN, Walther BA, et al. Adverse outcomes of long-term use of proton pump inhibitors: a systematic review and meta-analysis. Eur J Gastroenterol Hepatol. 2018;30:1395-405.

15. Trifan A, Stanciu C, Girleanu I, et al. Proton pump inhibitors therapy and risk of Clostridium difficile infection: systematic review and meta-analysis. World $\mathbf{J}$ Gastroenterol. 2017;23:6500-15.

16. Zhou B, Huang Y, Li H, et al. Proton-pump inhibitors and risk of fractures: an update meta-analysis. Osteoporos Int J Establ Result Coop Between Eur Found Osteoporos Natl Osteoporos Found USA. 2016;27:339-47.

17. Lin SM, Yang SH, Liang CC, et al. Proton pump inhibitor use and the risk of osteoporosis and fracture in stroke patients: a population-based cohort study. Osteoporos Int J Establ Result Coop Between Eur Found Osteoporos Natl Osteoporos Found USA. 2017;29:153-62.

18. Jacob L, Hadji P, Kostev K. The use of proton pump inhibitors is positively associated with osteoporosis in postmenopausal women in Germany. Clim J Int Menopause Soc. 2016;19:478-81.

19. Cao F, Chen CX, Wang M, et al. Updated meta-analysis of controlled observational studies: proton-pump inhibitors and risk of Clostridium difficile infection. J Hosp Infect. 2018;98:4-13.

20. Wan QY, Wu XT, Li N, et al. Long-term proton pump inhibitors use and risk of gastric cancer: a meta-analysis of 926386 participants. Gut. 2019;68:762-4.

21. Jiang K, Jiang X, Wen Y, et al. Relationship between long-term use of proton pump inhibitors and risk of gastric cancer: a systematic analysis. J Gastroenterol Hepatol. 2019;34:1898-1905.

22. Ahn JS, Park SM, Eom CS, et al. Use of proton pump inhibitor and risk of colorectal cancer: a meta-analysis of observational studies. Korean J Fam Med. 2012;33:272-9.

23. Chen S, Song X, Gao X, et al. Proton pump inhibitors and the risk of colorectal cancer: a meta-analysis. J Clin Gastroenterol. 2011;45:177.

24. Lai SW, Liao KF, Lai HC, et al. Use of proton pump inhibitors correlates with increased risk of colorectal cancer in Taiwan. Asia Pac J Clin Oncol. 2013;9:192-3.

25. Hwang IC, Chang J, Park SM. Emerging hazard effects of proton pump inhibitor on the risk of colorectal cancer in low-risk populations: a Korean nationwide prospective cohort study. PLoS ONE. 2017;12:e0189114.

26. Chu LC, Goggins MG, Fishman EK. Diagnosis and detection of pancreatic cancer. Cancer J (Sudbury, Mass). 2017;23:333-42.

27. Peng YC, Lin CL, Hsu WY, et al. Proton pump inhibitor use is associated with risk of pancreatic cancer: a nested case-control study. Dose Response Publ Int Hormesis Soc. 2018; 16:1559325818803283.

28. Hicks B, Friis S, Pottegard A. Use of proton pump inhibitors and risk of pancreatic cancer. Pharmacoepidemiol Drug Saf. 2018;27:926-30.

29. Kearns MD, Boursi B, Yang YX. Proton pump inhibitors on pancreatic cancer risk and survival. Cancer Epidemiol. 2017;46:80-4.

30. Lai SW, Sung FC, Lin CL, et al. Use of proton pump inhibitors correlates with increased risk of pancreatic cancer: a case-control study in Taiwan. Kuwait Med J. 2014;46:44-8. 
31. Bradley MC, Murray LJ, Cantwell MM, et al. Proton pump inhibitors and histamine-2-receptor antagonists and pancreatic cancer risk: a nested case-control study. $\mathrm{Br} \mathrm{J}$ Cancer. 2012;106:233-9.

32. Bosetti C, Lucenteforte E, Bracci PM, et al. Ulcer, gastric surgery and pancreatic cancer risk: an analysis from the International Pancreatic Cancer Case-Control Consortium (PanC4). Ann Oncol Off J Eur Soc Med Oncol. 2013;24:2903-10.

33. Hwang IC, Chang J, Park SM. Association between proton pump inhibitor use and the risk of pancreatic cancer: a Korean nationwide cohort study. PLoS ONE. 2018;13:e0203918.

34. Brusselaers N, Engstrand L, Lagergren J. Maintenance proton pump inhibition therapy and risk of oesophageal cancer. Cancer Epidemiol. 2018;53:172-7.

35. Brusselaers N, Lagergren J, Engstrand L. Duration of use of proton pump inhibitors and the risk of gastric and oesophageal cancer. Cancer Epidemiol. 2019;62:101585.

36. Brusselaers N, Wahlin K, Engstrand L, et al. Maintenance therapy with proton pump inhibitors and risk of gastric cancer: a nationwide population-based cohort study in Sweden. BMJ Open. 2017;7:e17739.

37. FASS (Farmacevtiska specialiteter i Sverige) [database on the Internet]. 2015. www.fass.se. Accessed 1 July 2019.

38. Brusselaers N, Lagergren J. Maintenance use of non-steroidal anti-inflammatory drugs and risk of gastrointestinal cancer in a nationwide population-based cohort study in Sweden. BMJ Open. 2018;8:e021869.

39. Breslow N, Day N. Statistical methods in cancer research: the design and analysis of cohort studies, chap 3, pp 82-86. Lyon 1987.

40. Statistics Sweden-Statistical Database Population Statistics. 2019. https://www.statistikdatabasen.scb.se/. Accessed 6 Apr 2016.

41. Wettermark B, Hammar N, Fored CM, et al. The new Swedish Prescribed Drug Register-opportunities for pharmacoepidemiological research and experience from the first 6 months. Pharmacoepidemiol Drug Saf. 2007;16:726-35.

42. Laine L, Nagar A. Long-term PPI use: balancing potential harms and documented benefits. Am J Gastroenterol. 2016;111:913-5.

43. Brusselaers N, Engstrand L, Lagergren J. PPI use and oesophageal cancer: what if the results are true? Cancer Epidemiol. 2018;54:139.

44. Public Health Agency of Sweden-Living Conditions and Lifestyle. 2019 [cited 201930 October 2019]; https://www. folkhalsomyndigheten.se/the-public-health-agency-of-sweden/liv ing-conditions-and-lifestyle/. Accessed 22 May 2018.

45. Singhi AD, Koay EJ, Chari ST, et al. Early detection of pancreatic cancer: opportunities and challenges. Gastroenterology. 2019;156:2024-40.

46. Kamisawa T, Wood LD, Itoi T, et al. Pancreatic cancer. Lancet. 2016;388:73-85.

47. Grahm AL, Andren-Sandberg A. Prospective evaluation of pain in exocrine pancreatic cancer. Digestion. 1997;58:542-9.

48. Keane MG, Horsfall L, Rait G, et al. A case-control study comparing the incidence of early symptoms in pancreatic and biliary tract cancer. BMJ Open. 2014;4:e005720.

49. Chien LN, Huang YJ, Shao YH, et al. Proton pump inhibitors and risk of periampullary cancers-a nested case-control study. Int J Cancer. 2016;138:1401-9.

50. Chuang SC, Lin CC, Peng CY, et al. Proton pump inhibitors increase the risk of cholecystitis: a population-based case-control study. Gut. 2019;68:1337-9.

51. Schneider J, Weidner W, Hapfelmeier A, et al. The use of proton pump inhibitors and the spectrum and number of biliary pathogens in patients with acute cholangitis. Aliment Pharmacol Ther. 2014;39:1194-203.

52. McDonald JM, Longnecker DS, Bell RH Jr. Effect of hypergastrinemia on pancreatic carcinogenesis. Am J Surg. 2002; $183: 441-4$

53. Le Bastard Q, Al-Ghalith GA, Gregoire M, et al. Systematic review: human gut dysbiosis induced by non-antibiotic prescription medications. Aliment Pharmacol Ther. 2018;47:332-45.

54. Imhann F, Bonder MJ, Vich Vila A, et al. Proton pump inhibitors affect the gut microbiome. Gut. 2016;65:740-8.

55. Zhernakova A, Kurilshikov A, Bonder MJ, et al. Populationbased metagenomics analysis reveals markers for gut microbiome composition and diversity. Science. 2016;352:565-9.

56. Bruno G, Zaccari P, Rocco G, et al. Proton pump inhibitors and dysbiosis: current knowledge and aspects to be clarified. World $\mathrm{J}$ Gastroenterol. 2019;25:2706-19.

57. Chhoda A, Lu L, Clerkin BM, et al. Current approaches to pancreatic cancer screening. Am J Pathol. 2019;189:22-35.

Publisher's Note Springer Nature remains neutral with regard to jurisdictional claims in published maps and institutional affiliations. 